\title{
Sclerosing stromal tumor of the ovary presenting as precocious puberty: Unusual presentation of the rare neoplasm
}

Jai Kumar Chaurasia, Nishat Afroz, Veena Maheshwari, Mohammed Naim

Department of Pathology, Jawaharlal Nehru Medical College, Aligarh Muslim University, Aligarh, Uttar Pradesh, India

Address for the Correspondence: Dr. Jai Kumar Chaurasia, Department of Pathology, Jawaharlal Nehru Medical College, Aligarh Muslim University, Aligarh - 202 002, Uttar Pradesh, India.

E-mail: dr.jaichaurasia@gmail.com

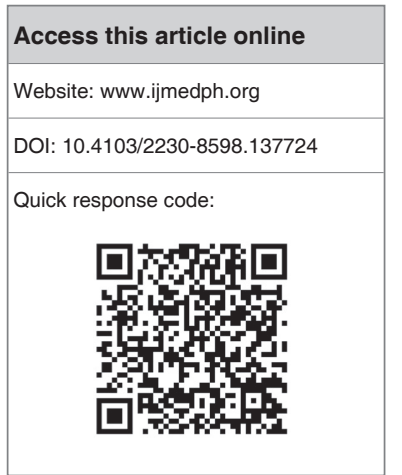

Sclerosing stromal tumor (SST) is a rare sex cord stromal neoplasm of the ovary. Precocious puberty resulting from this tumor is extremely rare. We report a case of SST of the ovary in a 7-year-old Indian girl, who presented with the complaints of excessive development of breasts, early menarche, growth of pubic hairs, accelerated growth and abdominal distension. On clinical examination, a large rightsided abdomino-pelvic mass was palpable. Magnetic resonance imaging revealed a large, heterogeneous, solid and cystic tumor in the right adenexal region, suggestive of an ovarian neoplasm. Hormonal profile showed markedly elevated estradiol and low follicle stimulating hormone levels. Clinical diagnosis of precocious puberty with right-sided ovarian mass was thus concluded. Right-sided salpingo-oophorectomy was then performed. Histopathology showed features consistent with SST of the ovary. Postoperatively, signs and symptoms of precocity gradually regressed and her serum estradiol level came down to normal.

Key words: Precocious, puberty, sclerosing stromal tumor

\section{INTRODUCTION}

Sclerosing stromal tumor (SST) is a rare benign sex cord stromal neoplasm of the ovary, which usually occurs in the second and third decades of life. ${ }^{[1]}$ Patients with this tumor often present with the complaints of pelvic mass, pain, abdominal distention, and menstrual irregularities. Anovulation, virilization and infertility may be present in these patients because SST is associated occasionally with estrogen and rarely androgen secretion. ${ }^{[2]}$ Precocious puberty resulting from this tumor is extremely rare. ${ }^{[3,4]}$ This case is being reported due to unique and unusual presentation of rare SST of the ovary. To the best of our knowledge, this is the first reported case of SST resulting in precocious puberty from India.

\section{CASE REPORT}

A 7-year-old Indian girl was presented by her mother to Gynecology Outpatient Department with the complaints of excessive development of her breasts for the last 1 year. She had attained menarche 8 months back. Her mother noticed growth of pubic hairs, accelerated body growth and abdominal distension for the last 4 months. Family history, antenatal, perinatal and developmental history was unremarkable. History of local trauma, sexual abuse, drug intake and any other systemic illness were absent. On clinical examination, a right-sided, large abdomino-pelvic mass was palpable. The mass was firm in consistency, immobile, measuring about $8 \mathrm{~cm} \times 5 \mathrm{~cm} \times 3 \mathrm{~cm}$ with well demarcated margins. Pelvic magnetic resonance imaging revealed a large, well-defined, heterogeneous solid and cystic mass measuring $8.5 \mathrm{~cm} \times 5.5 \mathrm{~cm} \times 4 \mathrm{~cm}$ in the right adenexal region [Figure 1a]. Right ovary was not separately definable from the mass. The left ovary appeared normal. Patient's height was 127 $\mathrm{cm}$ and weight was $27 \mathrm{~kg}$. She was Tanner stage IV for breast development and Tanner stage III for pubic hair. There were no signs of virilization such as facial hair, deepening of voice, enlargement of clitoris, adrenocortical and central nervous system dysfunction, hypothyroidism, hyperparathyroidism, cushing's disease or any endocrinopathy. 
Routine hematological investigations and liver and renal function tests were found to be within normal limits. Hormonal profile revealed markedly elevated serum estradiol level (440 pg/ml, reference value for prepubertal females $<10 \mathrm{pg} / \mathrm{ml}$ ). Her follicle stimulating hormone (FSH) level was suppressed $(<1 \mathrm{IU} / \mathrm{ml})$. Patient's beta human chorionic gonadotropin ( $\beta$-hCG) $(1.5 \mathrm{mIU} /$ $\mathrm{ml})$, serum carcino-embyonic antigen $(1.0 \mathrm{ng} / \mathrm{ml})$, alpha-fetoprotein $(3.0 \mathrm{ng} / \mathrm{ml})$, thyroid stimulating hormone $(0.4 \mathrm{mIU} / \mathrm{l})$ and total thyroxine (T4) level $(8 \mu \mathrm{g} / \mathrm{dl})$, were normal for her age.

Clinical and MRI findings suggested diagnosis of an ovarian tumor with precocious puberty. Right-sided salpingo-oophorectomy was performed and specimen was submitted for histopathological diagnosis.

The gross examination of the resected specimen revealed an encapsulated ovarian mass without any capsular breach, measuring $10 \mathrm{~cm} \times 7.5 \mathrm{~cm} \times 6 \mathrm{~cm}$ and weighing $420 \mathrm{~g}$ with fallopian tube measuring $6 \mathrm{~cm} \times 3 \mathrm{~cm}$ on the tumor surface [Figure 1b]. The outer surface was white and smooth. Cut-surface showed gray-white solid areas with occasionally yellowish foci, rubbery consistency and multiple small cystic spaces without any hemorrhage or necrosis.

Hematoxylin and Eosin stained sections showed tumor comprising of spindle and round vacuolated clear cells with micro capillary vessels forming pseudo-lobules separated by hypocellular bands of edematous fibro-collagenous tissue [Figure 1c]. Some of the thin walled vessels showed hemangiopericytoma like pattern [Figure 1d]. Mitosis and necrosis were not appreciable. Tumor was periodic acid Schiff and mucicarmine stains negative indicative of glycol-mucin negativity of the clear cells. The fallopian tube showed normal morphology.

Silver impregnation highlighted the vacuolated cells and blood vessels in the tumor pseudo-lobules. Van-geison stain showed

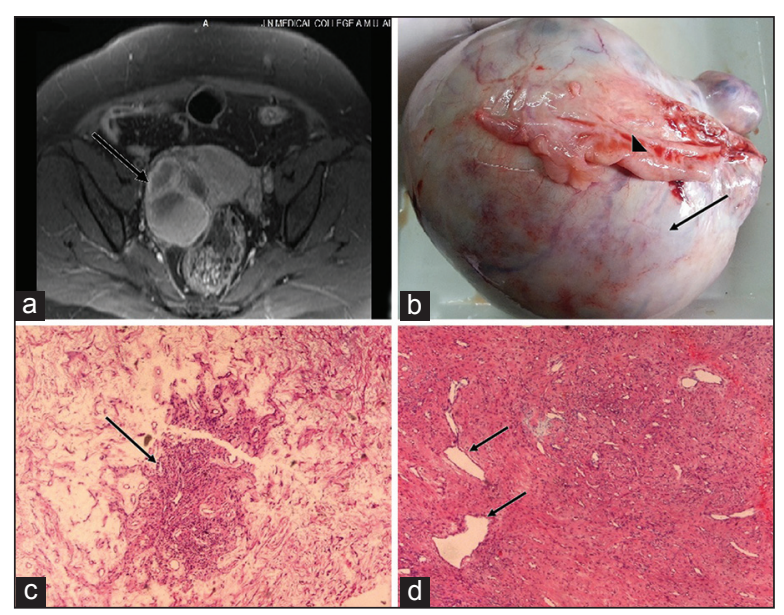

Figure 1: (a) T2-weighted magnetic resonance image showing heterogeneous, solid-cystic tumor in right adenexal region (arrow), (b) ovarian tumor with gray-white surface (arrow) and attached fallopian tube (arrow head), (c) tumor pseudo-lobule (arrow) with surrounding edematous stroma ( $\mathrm{H}$ and $\mathrm{E}, \times 50)$, (d) pseudo-lobule with thin walled hemangiopericytoma like blood vessels (arrow) and fibro-collagenous stroma ( $\mathrm{H}$ and $\mathrm{E}, \times 50)$ collagen producing spindle cells. Smooth muscle actin immunostain demonstrated the presence of smooth-muscle-spindle-cells, diffusely distributed in the tumor section with focal accentuation in the vascular areas, suggestive of proliferation of smooth muscle cells in vessel walls [Figure 2a and b]. Vimentin stain showed a similar pattern of positivity in the tumor section [Figure 2c]. The cytokeratin marker was negative. Monoclonal anti alpha-inhibin antibody was used to demonstrate the inhibin expression. The inhibin was positive, expressed as cytoplasmic granular positivity in the vacuolated tumor cells [Figure 2d], suggestive of a sex cord stromal origin of the tumor. Based on histological and immuno-histological findings, a diagnosis of SST of the ovary was made.

Postoperative recovery of the patient was uneventful. Her serum estradiol came down to level of $<10 \mathrm{pg} / \mathrm{ml}$ within a month. Her menses stopped and signs and symptoms of precocious puberty gradually regressed and disappeared. Patient was under monthly follow-up during the last 6 months and did not show any signs of recurrence and showed normal serum estradiol and FSH and 24-h urinary estrogenic hormonal levels. She will be followed with pelvic ultrasonography, MRI and hormone levels for any recurrence of the tumor every 3 monthly until 1 year, followed by 6 monthly until another next 5 years. A gonadotropin releasing hormone $(\mathrm{GnRH})$ stimulation test will be planned in the future for distinguishing commencement of normal physiological pubertal hormonal changes from any recurrence of precocious pseudopuberty.

\section{DISCUSSION}

In the present case, precocious puberty with fibro-collagenous angiomatous lutein cell ovarian tumor with hyper-estrogenism, in a 7-year-old girl, was diagnostic of ovarian SST. Incidence of this tumor in prepubertal age causing precocious puberty was rarely reported in the earlier literature. ${ }^{[3]}$ In only one Chinese female child, SST with signet ring cell tumor characteristics was reported at an early age of 4 years. ${ }^{[4]}$

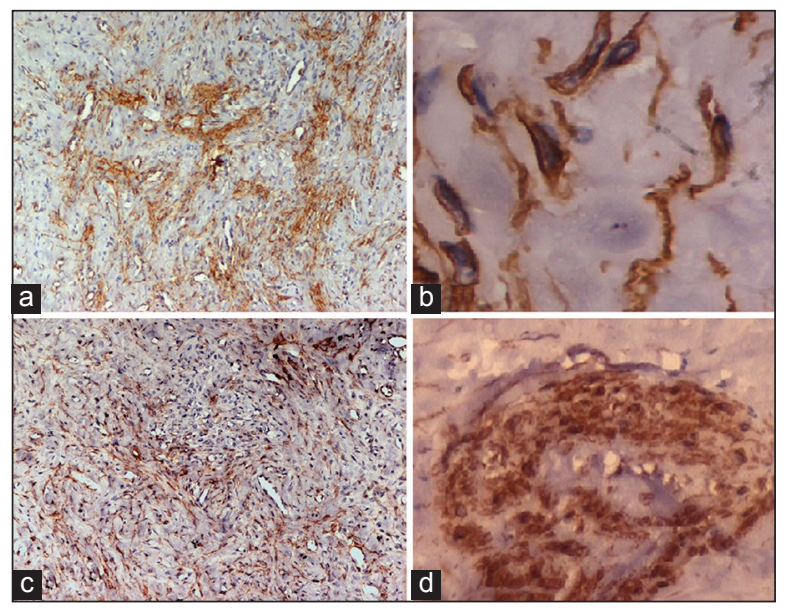

Figure 2: Spindle tumor cells showing smooth muscle actin positivity $(a, \times 50, b, \times 1000)$ and vimentin positivity $(c, \times 50)$, the vacuolated tumor cells showing cytoplasmic positivity for inhibin $(d, \times 500)$ 
Peripheral or gonadotropin independent precocious puberty constituted $<20 \%$ of the total precocity cases. ${ }^{[5]}$ Elevated level of estradiol and suppressed level of FSH, in the present case, suggested that precocity was not central and was $\mathrm{GnRH}$ independent, that is not from the hypothalamo-pituitary-ovarian axis dysfunction, but due to the peripheral high estrogen production by SST.

The differential diagnoses in this case included other estrogen secreting ovarian neoplasia in children like juvenile granulosa cell tumor (JGCT), massive ovarian edema and other germ cell tumors.

Juvenile granulosa cell tumor which accounts for approximately $10 \%$ cases of isosexual precocity in the girls. ${ }^{[6]}$ The JGCT are partly solid and cystic tumor similar to the SST, causing diagnostic confusion. However, , histopathologically, JGCT lacks the typical pseudo-lobular pattern of SST, and instead have sheets or nodular aggregates of neoplastic granulosa cells.

Massive ovarian edema causes marked enlargement of the ovary and may present with signs and symptoms of hormone secretion like hirsutism and precocious puberty. ${ }^{[7]}$ However, the preserved ovarian tissue within the edematous stroma and absence of heterogeneity distinguishes it from the SST.

Germ cell tumors of the ovary may manifest with excessive hCG production with resultant luteinisation of stroma, which may produce steroid hormones resulting in hyper-estrogenism. ${ }^{[8]}$ Nongestational choriocarcinoma are vascular solid tumors, commonly occurring in children and young adults and may manifest with isosexual precocity (approximately $50 \%$ of cases). ${ }^{[8]}$ But these tumors present with elevated levels of total and $\beta$-hCG, which was absent in the present case of SST.

Pure dysgerminomas do not secrete hormones; however 5\% of the tumors may contain syncytiotrophoblasts which produce $\beta$-hCG, resulting in estrogenic manifestations. ${ }^{[8]}$ Similarly, mature teratomas occur in young females and constitute about $50 \%$ of ovarian tumors in children. Virilization and hyper-estrogenism due to mature cystic teratomas have been reported, but predominantly in the postmenopausal women. ${ }^{[9]}$

Unilateral salpingo-oophorectomy for removal of SST ovary, as was performed in the present case is considered as fertility-sparing surgery. ${ }^{[10]}$ Although, the chances of conception are reduced, the patient will be expected to remain fertile because of the normal functions of opposite ovary and salpinx and will be followed-up until normal physiological hormonal and pubertal changes like commencement of menses will take over.

\section{CONCLUSION}

Sclerosing stromal tumor is a rare sex cord stromal neoplasm of the ovary with distinct histological and immuno-histochemical features. Rarely, it may present as precocious puberty. The diagnosis of SST of the ovary should be concluded by extensive histopathological, hormonal and immuno-histochemical examinations to distinguish it from the other ovarian tumors.

\section{REFERENCES}

1. Gwin K, Mariño-Enríquez A, Martel M, Reyes-Múgica M. Sclerosing stromal tumor: An important differential diagnosis of ovarian neoplasms in childhood and adolescence. Pediatr Dev Pathol 2009;12:366-70.

2. Tanaka YO, Tsunoda H, Kitagawa Y, Ueno T, Yoshikawa H, Saida Y. Functioning ovarian tumors: Direct and indirect findings at MR imaging. Radiographics 2004;24 Suppl 1:S147-66.

3. Chang YW, Hong SS, Jeen YM, Kim MK, Suh ES. Bilateral sclerosing stromal tumor of the ovary in a premenarchal girl. Pediatr Radiol 2009;39:731-4.

4. He Y, Yang KX, Jiang W, Wang DQ, Li L. Sclerosing stromal tumor of the ovary in a 4-year-old girl with characteristics of an ovarian signet-ring stromal tumor. Pathol Res Pract 2010;206:338-41.

5. Lee CT, Tung YC, Tsai WY. Etiology and clinical features of isosexual precocious puberty in Taiwanese girls: 23 years' experience in National Taiwan University Hospital. J Pediatr Endocrinol Metab 2009;22:947-53.

6. Saeed GA, Farooq N. Precocious pseudopuberty due to juvenile granulosa cell tumor. J Coll Physicians Surg Pak 2003;13:287-8.

7. Cepni I, Ocal P, Erkan S, Saricali FS. Massive edema of the ovary diagnosed with laparoscopic biopsy and frozen section. J Postgrad Med 2005;51:336-7.

8. Shanbhogue AK, Shanbhogue DK, Prasad SR, Surabhi VR, Fasih N, Menias CO. Clinical syndromes associated with ovarian neoplasms: A comprehensive review. Radiographics 2010;30:903-19.

9. Hoffman JG, Strickland JL, Yin J. Virilizing ovarian dermoid cyst with leydig cells. J Pediatr Adolesc Gynecol 2009;22:e39-40.

10. Tsai HW, Ko CC, Yeh CC, Chen YJ, Twu NF, Chao KC, et al. Unilateral salpingo-oophorectomy as fertility-sparing surgery for borderline ovarian tumors. J Chin Med Assoc 2011;74:250-4.

How to cite this article: Chaurasia JK, Afroz N, Maheshwari V, Naim M. Sclerosing stromal tumor of the ovary presenting as precocious puberty: Unusual presentation of the rare neoplasm. Int J Med Public Health 2014;4:307-9.

Source of Support: Nil, Conflict of Interest: None declared. 